\title{
IQTISHODUNA
}

Vol. 16 (1), 2020

P-ISSN: 1829-524X, E-ISSN: 2614-3437

\section{Pengaruh Upah Minimum Kabupaten/Kota (UMK) dan Pembangunan Manusia Berbasis Maqashid Syariah terhadap Jumlah Kemiskinan di Kabupaten Grobogan Jawa Tengah}

\author{
Ria Safitri ${ }^{1}$, Jadzil Baihaqi ${ }^{*}$, Supriyadi ${ }^{3}$ \\ 1,2,3 Institut Agama Islam Negeri Kudus, Indonesia
}

区 Corresponding Author:

Nama Penulis: Jadzil Baihaqi

E-mail: jadzilbaihaqi@iainkudus.ac.id

\begin{abstract}
This study aims to determine the effect of City Minimum Wage and human development based on maqashid shari'a on the amount of poverty in Grobogan, Central Java. This study uses a quantitative approach with secondary data types obtained from the Central Statistics Agency (BPS) and the Office of the Ministry of Religion Grobogan Regency. This research method uses multiple regression analysis techniques with time series data from 2011 to 2017. Data analysis in this study uses Eviews 7 software. The results showed that the city minimum wage had a negative effect on the amount of poverty in Grobogan Regency. Whereas human development based on maqashid shari'a has a negative and not significant effect on the amount of poverty in Grobogan Regency. Human development based on maqashid shari'a has a negative and insignificant effect due to poverty measurement used by the Central Statistics Agency (BPS) using the concept of ability to meet basic needs (basic need approach). With this approach, poverty is seen as an inability from the economic side to meet the basic needs of food and non-food which are measured in terms of expenditure and income, so that other components cannot be directly linked to poverty.
\end{abstract}

Keywords: Poverty, City Minimum Wages, Human Development Index, Maqashid Sharia.

\begin{abstract}
Abstrak: Penelitian ini bertujuan untuk mengetahui pengaruh Upah Minimum Kabupaten/Kota (UMK) dan pembangunan manusia berbasis maqashid Syariah terhadap jumlah kemiskinan di Kabupaten Grobogan Jawa Tengah. Penelitian ini menggunakan pendekatan kuantitatif dengan jenis data sekunder yang diperoleh dari Badan Pusat Statistik dan Kantor Kementrian Agama Kabupaten Grobogan. Metode penelitian ini menggunakan teknik analisis regresi berganda dengan data time series tahun 2011 sampai tahun 2017. Analisis data dalam penelitian ini menggunakan bantuan Software Eviews 7. Hasil penelitian menunjukkan upah minimum kota berpengaruh negatif terhadap jumlah kemiskinan di Kabupaten Grobogan. Sedangkan pembangunan manusia berbasis maqashid Syariah berpengaruh negatif dan tidak signifikan terhadap jumlah kemiskinan di Kabupaten Grobogan. Pembangunan manusia berbasis maqashid Syariah berpengaruh negatif dan tidak signifikan dikarenakan pengukuran kemiskinan yang digunakan oleh Badan Pusat Statistik menggunakan konsep kemampuan memenuhi kebutuhan dasar. Dengan pendekatan ini, kemiskinan dipandang sebagai ketidakmampuan dari sisi ekonomi untuk memenuhi kebutuhan dasar makanan dan bukan makanan yang diukur dari sisi pengeluaran dan pendapatan, sehingga komponen lain tidak dapat langsung dikaitkan dengan kemiskinan tersebut.
\end{abstract}

Kata kunci: Kemiskinan, UMK, Indeks Pembangunan Manusia, Maqashid Syariah. 
| Draft awal Agustus 2019 |Diterima Februari 2020 | Terbit April 2020 |

| DOI: http://dx.doi.org/10.18860/iq.v16i1.7498

\section{Cara mencitasi:}

Safitri, R., Baihaqi,J., Supriyadi. (2020). Pengaruh Upah Minimum Kabupaten/Kota (UMK) dan Pembangunan Manusia Berbasis Maqashid Syariah terhadap Jumlah Kemiskinan di Kabupaten Grobogan Jawa Tengah. Iqtishoduna. Vol. 16 (1): pp 39-58.

\section{Pendahuluan}

Indonesia telah melalui transformasi yang mengagumkan dalam lima belas tahun terakhir. Menurut World Bank, angka kemiskinan nasional telah berkurang setengahnya, dari 24 persen di tahun 1999 menjadi 11.3 persen di tahun 2014. Rata-rata pertumbuhan ekonomi bertahan di angka sekitar 6 persen dalam dasawarsa terakhir. Indonesia juga menjadi anggota G-20, satusatunya dari Asia Tenggara (Dokumen World Bank, 2015).

G-20 atau Kelompok 20 ekonomi utama adalah kelompok 19 negara dengan perekonomian besar di dunia ditambah dengan Uni Eropa. Secara resmi G-20 dinamakan The Group of Twenty (G-20) Finance Ministers and Central Bank Governors atau Kelompok Duapuluh Menteri Keuangan dan Gubernur Bank Sentral. Namun, perjalanan menuju kesejahteraan bersama masih belum selesai, Indonesia berisiko tidak membantu rakyat miskin dan rentannya pengentasan kemiskinan mulai stagnan, dengan penurunan yang mendekati nol pada tahun 2014. Ketimpangan pendapatan naik dengan cepat dan hampir sepertiganya berasal dari ketimpangan kesempatan.

Kabupaten Grobogan merupakan salah satu kota dengan jumlah penduduk terbesar di Jawa Tengah, jumlah penduduk juga sejalan dengan jumlah kemiskinan yang terjadi di Kabupaten Grobogan. Berikut adalah data persentase perbandingan kemiskinan di Kabupaten Grobogan dengan Kabupaten/ Kota terdekat:

Tabel 1. Persentase Perbandingan Kemiskinan Kabupaten Grobogan dengan Kabupaten/ Kota Terdekat Periode 2014-2017

\begin{tabular}{lcccc}
\hline Kabupaten & $\mathbf{2 0 1 4}$ & $\mathbf{2 0 1 5}$ & $\mathbf{2 0 1 6}$ & $\mathbf{2 0 1 7}$ \\
\hline Grobogan & 13.86 & 13.68 & 13.57 & 13.27 \\
Blora & 13.66 & 13.52 & 13.33 & 13.04 \\
Pati & 12.06 & 11.95 & 11.65 & 11.38 \\
Kudus & 7.99 & 7.73 & 7.65 & 7.59 \\
\hline
\end{tabular}

Sumber : Badan Pusat Statistik Jawa Tengah, data diolah 
Berdasarkan Tabel 1, persentase perbandingan kemiskinan Kabupaten Grobogan dengan Kabupaten/ Kota terdekat menunjukkan bahwa tingkat penduduk miskin di Kabupaten Grobogan masih tergolong cukup besar.

Upah minimum di Indonesia ditetapkan dengan dua maksud, pertama, untuk meningkatkan standar hidup buruh. Kedua, upah minimum sebagai jaring pengaman (safety net) yang bertujuan untuk melindungi pekerja dengan upah rendah. Upah minimum dimaksudkan sebagai jaring pengaman karena banyaknya tenaga kerja tidak terampil dan lemahnya serikat buruh sehingga memiliki bargaining power yang rendah.Upah minimum di Indonesia pada awalnya ditetapkan dengan berdasarkan pada Kebutuhan Hidup Layak atau KHL (Kurniawati, Gunawan, \& Indrasari, 2017). Jika efektif, upah minimum dapat digunakan sebagai salah satu alat untuk mengurangi kemiskinan karena dapat membantu penduduk miskin untuk keluar dari kemiskinan.

Selain upah minimum kota yang sangat berperan banyak terhadap penurunan kemiskinan, Indeks Pembangunan Manusia atau HDI (Human Development Index) juga menjadi salah satu faktor yang dapat mempengaruhi jumlah kemiskinan. Human Development Index (HDI) atau disebut juga dengan Indeks Pembangunan Manusia (IPM) sebagai ukuran kinerja pembangunan secara keseluruhan dibentuk melalui pendekatan tiga dimensi dasar, yaitu umur panjang dan sehat, pengetahuan, dan penghidupan yang layak.

Keberadaan HDI yang ditawarkan oleh United Nations Development Programme (UNDP) sebagai salah satu alat yang dipakai untuk mengukur tingkat pembangunan manusia mungkin dapat menjadi indikator yang paling komprehensif, tetapi tidak sepenuhnya kompatibel dan cukup untuk mengukur pembangunan manusia dalam perspektif islam. Teori dan konsep yang mendasari untuk pembangunan HDI tidak didasarkan pada maqashid Syariah. Untuk mengukur tingkat pembangunan manusia di negara yang mayoritas penduduknya beragama islam akan lebih tepat jika dilakukan dengan menggunakan Islamic Human Development Index (I-HDI) yang mana teori dan konsepnya berdasarkan pada perspektif islam (Septiarini \& Herianingrum, 2017).

Berdasarkan penelitian yang dilakukan oleh Anto dalam Introduction an Islamic Human Development Index (I-HDI) to Measure Development in OIC Countries (2009), I-HDI dihitung berdasarkan data yang menggambarkan lima dimensi maqashid Syariah. Untuk dimensi agama (ad-dien) indikator yang digunakan yaitu data angka kriminalitas dan angka partisipasi siswa sekolah agama. Dimensi jiwa (an-nafs) indikator yang dipakai yaitu data 
angka harapan hidup. Sementara itu, untuk dimensi intelektual (al-aql) diguakan indikator data angka melek huruf dan rata-rata lama sekolah. Untuk dimensi keturunan (an-nasl) digunakan dua indikator yaitu data angka kelahiran total dan angka kematian bayi. Sedangkan untuk dimensi harta (almaal) digunakan gabungan dua indikator yaitu indikator kepemilikan harta oleh individu dan indikator distribusi pendapatan. Untuk indikator kemiskinan atas harta yang dipakai yaitu pengeluaran perkapita riil disesuaikan, dan untuk indikator distribusi pendapatan digunakan data indeks kedalaman kemiskinan (Anto, 2011). Tujuan dari penelitian ini adalah untuk mengetahui pengaruh upah minimum kabupaten/kota (UMK) dan pembangunan manusia berbasis maqashid syariah terhadap jumlah kemiskinan di Kabupaten Grobogan Jawa Tengah.

\section{Kajian Pustaka}

\section{Konsep dan Teori Kemiskinan}

Kemiskinan adalah kondisi keterbatasan kemampuan untuk memenuhi kebutuhan hidup secara layak seperti keterbatasan dalam pendapatan, keterampilan, kondisi kesehatan, penguasaan aset ekonomi, ataupun akses informasi. Pengukuran ini bersifat materi atau pendekatan moneter. Pengukuran dengan pendekatan moneter dapat dilakukan dengan menggunakan data pengeluaran sebagai pendekatan rumah tangga. Kemudian data pengeluaran ini diperbandingkan dengan suatu batas nilai tukar rupiah yang diperlukan untuk memenuhi kebutuhan hidup minimum. Batas ini sering disebut sebagai garis kemiskinan. penduduk yang pengeluarannya lebih kecil daripada garis kemiskinan ini disebut penduduk miskin (Isdijoso, Suryahadi, \& Akhmadi, 2016).

\section{Konsep dan Teori Upah}

Berdasarkan ketentuan Pasal 1 angka 30 Undang-undang No.13 Tahun 2003, upah adalah hak pekerja atau buruh yang diterima dan dinyatakan dalam bentuk uang sebagai imbalan dari pengusaha atau pemberi kerja kepada pekerja atau buruh yang ditetapkan dan dibayarkan menurut suatu perjanjian kerja, kesepakatan, atau peraturan perundang-undangan, termasuk tunjangan bagi pekerja atau buruh dan keluarganya atas suatu pekerjaan dan/atau jasa yang telah atau akan dilakukan.

Secara sederhana upah dapat dikatakan sebagai gaji yang dibayarkan kepada pekerja karena mereka ikut andil dalam sebuah proses produksi. Dalam sistem Kapitalis ada beberapa teori yang menerangkan tentang upah: (1) Subsistence theory of wages, teori ini menjelaskan bahwa upah dibatasi dengan tingkat kebutuhan dasar yang diperlukan untuk memenuhi biaya hidup seorang pekerja dan keluarganya. Ini karena jika terdapat kelebihan 
dalam upah, maka akan mendorong pertambahan populasi penduduk yang mengakibatkan bertambahnya penawaran tenaga kerja dan akan berdampak terhadap penurunan upah. (2) Wage fund theory of wages, teori ini muncul pada abad ke-19. Teori ini didasarkan bahwa upah dapat berubah sesuai dengan unsur yang mempengaruhinya, yaitu permintaan dan penawaran buruh. Sedangkan faktor permintaan buruh dipengaruhi oleh jumlah dana yang disediakan untuk membayar upah itu sendiri. Jadi, perubahan kadar upah dipengaruhi oleh dua faktor utama yang berkaitan dengan permintaan dan penawaran buruh. Teori ini berbeda dengan teori sebelumnya karena teori sebelumnya menekankan bahwa kadar upah dipengaruhi oleh jumlah penduduk. (3) Marginal productivity theory of wages, teori ini didasarkan pada produktivitas marginal buruh. Maksudnya, jumlah upah buruh tergantung pada kemampuan buruh dalam memproduksi barang atau jasa. Semakin banyak hasil produksi buruh, maka semakin bertambah banyak upah yang diterima. Pengusaha akan menambah upah pekerja sampai batas pertambahan produktivitas marjinal buruh minimal sama dengan upah yang diberikan kepada mereka. Oleh karena itu teori ini sangat sesuai dengan sistem kapitalis dalam memaksimumkan keuntungan karena dengan teori ini pekerja akan termotivasi untuk menghasilkan barang dan jasa yang lebih banyak. (4) Bargaining theory of wage, teori ini mengandalkan ada batas minimal dan maksimal upah. Dan upah yang berlaku merupakan hasil kesepakatan dan persetujuan antara kedua belah pihak. (5) Teori daya beli, teori ini mendasarkan permintaan pasar atas barang dengan upah. Agar barang terbeli maka upah harus tinggi, jika upah rendah maka daya beli tidak ada dan barang tidak laku. Dan jika hal itu dibiarkan maka akan terjadi pengangguran besar-besaran. (6) Teori upah hukum alam, teori ini menyatakan bahwa upah ditetapkan atas dasar biaya yang diperlukan untuk memelihara atau memulihkantenaga buruh yang telah dipakai untuk proses produksi (Ridwan, 2013).

\section{Konsep dan Teori Pembangunan Manusia Berbasis Maqashid Syariah}

Pembangunan dalam perspektif Islam memiliki sifat unik yang membuatnya menjadi sangat berbeda dengan pandangan dalam konvensional. Dalam islam tujuan dari pembangunan ekonomi adalah untuk mencapai kesejahteraan menyeluruh dan menyeluruh baik di dunia dan akhirat. Karakteristik lain dari pengembangan ekonomi islam, indikator konvensional saja tidak cukup menjadi ukuran tingkat pembangunan ekonomi di negara mayoritas muslim (Anto, 2011).

I-HDI atau pembangunan manusia berbasis maqashid Syariah merupakan alat yang digunakan untuk mengukur pembangunan manusia dalam perspektif Islam. I-HDI mengukur pencapaian tingkat kesejahteraan 
manusia dengan terpenuhinya kebutuhan (maslahah) dasar agar manusia dapat hidup bahagia di dunia dan akhirat (mencapai falah). Menurut alSyatibi, maslahah dasar bag manusia terdiri dari lima hal, yaitu agama (addien), jiwa (an-nafs), akal (al-aql), keturunan (an-nasl), dan harta (al-maal). Kelima hal tersebut merupakan kebutuhan dasar manusia, yaitu kebutuhan yang mutlak harus dipenuhi agar manusia dapat hidup bahagia di dunia dan akhirat. Jika salah satu dari kebutuhan dasar tersebut tidak terpenuhi atau terpenuhi dengan tidak seimbang, maka kebahagiaan hidup juga tidak tercapai dengan sempurna. Ada lima dimensi ukuran Islamic Human Development Index yaitu sebagai berikut:

1) Hifdzu ad-Dien

Beberapa ayat al-Qur'an yang berkaitan dengan hifdzu ad-dien antara lain adalah QS. al-Ankabut (29): 45, tentang perintah shalat. Artinya: "Bacalah Kitab (Al-Qur'an) yang telah diwahyukan kepadamu (Muhammad) dan laksanakanlah shalat. Sesungguhnya shalat itu mencegah dari (perbuatan) keji dan mungkar. Dan (ketahuilah) mengingat Allah (shalat) itu lebih besar dari ibadah yang lain. Allah mengetahui apa yang kamu kerjakan.” Berdasarkan pada ayat tersebut, diketahui bahwa terdapat beberapa indikator yang dapat digunakan untuk membentuk index ad-dien. Secara umum, indikator-indikator tersebut dapat dikategorikan menjadi dua, yaitu indikator positif dan negatif. Beberapa indikator yang berdimensi positif sebagian di ambil dari lima rukun Islam, kecuali syahadat yang terdiri dari: jumlah masjid, puasa, zakat, haji, jumlah ulama, partisipasi sekolah agama, dan realisasi dana amal. Sementara itu, indikator yang berdimensi negatif terdiri dari angka kriminalitas dan Corruption Perception Index (CPI) (Anto, 2011).

2) Hifdzu an-Nafs

Beberapa ayat al-Qur'an yang berkaitan dengan hifdzu an-nafs antara lain adalah QS. al-Baqarah (2): 168, perintah memakan makanan halal dan baik. Artinya: "Hai sekalian manusia, makanlah yang halal lagi baik dari apa yang terdapat di bumi, dan janganlah kamu mengikuti langkah-langkah syaitan, karena sesungguhnya syaitan itu adalah musuh yang nyata bagimu". Berdasarkan ayat tersebut, dapat diketahui bahwa terdapat beberapa indikator yang dapat digunakan untuk membentuk index an-nafs. Secara umum, indikator-indikator tersebut dapat dikategorikan menjadi indikator yang berdimensi positif terdiri dari: angka harapan hidup, mordibilitas, angka kunjungan ke fasilitas kesehatan, sarana kesehatan, tenaga kesehatan, dan imunisasi. Sementara itu, beberapa indikator yang berdimensi negatif terdiri dari: 
drug prevalance dan smoking prevalance. Beberapa indikator yang telah disebutkan di atas merupakan indikator yang dapat digunakan untuk membentuk index an-Nafs (Rahmatullah, 2018).

3) Hifdzu al-'Aql

Beberapa ayat al-Qur'an yang berkaitan dengan hifdzu al-'aql antara lain adalah QS. al-'Alaq (96): 1-5, perintah untuk menuntut ilmu. Artinya: “(1) Bacalah dengan (menyebut) nama Tuhanmu yang menciptakan. (2) Dia telah menciptakan manusia dari segumpal darah. (3) Bacalah, dan Tuhanmulah yang maha pemurah. (4) yang mengajar (manusia) dengan perantaraan kalian. (5) Dia mengajar kepada manusia apa yang tidak diketahuinya". Berdasarkan pada ayat di atas, dapat diketahui bahwa terdapat beberapa indikator yang dapat digunakan untuk membentuk index al-'aql. Index al-'aql merupakan indeks yang digunakan untuk mengukur dimensi pengetahuan. Beberapa indikator yang dapat digunakan yaitu: angka harapan lama sekolah, angka partisipasi sekolah, rata-rata lama sekolah, jumlah lembaga pendidikan, tenaga pengajar, akses ke internet, angka melek huruf, angka buta huruf, jumlah hak paten, dan pengeluaran pendidikan oleh rumah tangga.

4) Hifdzu an-Nasl

Beberapa ayat al-Qur'an yang berkaitan dengan hifdzu an-nasl antara lain adalah QS. an-Nuur (24): 32, perintah untuk menikah. Artinya: "Dan kawinkanlah orang-orang yang sendirian diantara kamu, dan orang-orang yang layak (berkawin) dari hamba-hamba sahayamu yang lelaki dan hamba-hamba sahayamu yang perempuan jika mereka miskin Allah akan memampukan mereka dengan kurnia-Nya dan Allah Maha luas (pemberian-Nya) lagi maha mengetahui". Beberapa indikator yang berdimensi positif terdiri dari: angka reproduksi kasar, rata-rata jumlah kelahiran, angka kelahiran total, dan anak lahir hidup. Beberapa indikator yang berdimensi negatif terdiri dari: rata-rata umur menikah, tingkat perceraian, angka kematian bayi, angka kematian ibu, angka kematian balita, dan angka kematian anak. Beberapa indikator yang telah disebutkan di atas merupakan indikator yang dapat digunakan untuk membentuk index an-nasl (Rahmatullah, 2018).

5) Hifdzu al-Maal

Beberapa ayat al-Qur'an yang berkaitan dengan hifdzu al-maal antara lain adalah QS. Hud (11): 61, perintah untuk memakmurkan bumi. Artinya: "Dan kepada Tsamud (Kami utus) saudara mereka shaleh. Shaleh berkata: Hai kaumku, sembahlah Allah, sekali-kali tidak ada bagimu Tuhan selain Dia. Dia telah menciptakan kamu dari bumi (tanah) 
dan menjadikan kamu pemakmurnya, karena itu mohonlah ampunanNya, kemudian bertobatlah kepada-Nya, sesungguhnya Tuhanku amat dekat (rahmat-Nya) lagi memperkenankan (doa hamba-Nya)". Beberapa indikator yang mewakili kepemilikan atas harta yaitu pendapatan per kapita dan rata-rata pengeluaran per kapita. Indikator yang mewakili pertumbuhan pendapatan yaitu pertumbuhan ekonomi dan GDP/pertumbuhan penduduk. Indikator yang mewakili distribusi pendapatan yaitu: rasio gini, garis kemiskinan, indeks kemiskinan manusia, persentase penduduk miskin, indeks kedalaman kemiskinan, dan indeks keparahan kemiskinan (Rahmatullah, 2018).

\section{Pengembangan Hipotesis}

Tingkat kemiskinan di Indonesia yang masih tinggi mencerminkan adanya masalah kesejahteraan pada sebagian masyarakat Indonesia. Oleh karena itu, masalah kemiskinan harus diselesaikan karena menyangkut kesejahteraan seseorang dan dapat mengancam keberlangsungan hidup seseorang. Grobogan adalah salah satu Kabupaten di Jawa Tengah yang masih mempunyai tingkat kemiskinan tinggi dibandingkan dengan Kabupaten sekitar. Pemerintah memiliki peran yang penting dalam mengatasi masalah kemiskinan yaitu dengan membuat kebijakan yang dapat mengurangi angka kemiskinan.

\section{Hubungan Upah Minimum Kota dengan Kemiskinan}

Kebijakan ekonomi di bidang ketenagakerjaan yang menjadi isu penting di negara Indonesia salah satunya adalah kebijakan upah minimum yang telah ditentukan oleh pemerintah. Tujuan penetapan upah minimum adalah menjamin pekerja/buruh mendapat penghasilan minimum untuk hidup layak, memberi kesejahteraan kepada pekerja dan mempersempit kesenjangan pendapatan. Menurut UU No. 13/2003 Pasal 88, upah minimum diarahkan pada pencapaian kebutuhan hidup layak dengan memperhatikan produktivitas dan pertumbuhan ekonomi(Undang-Undang Republik Indonesia, 2003).Upah minimum dimaksudkan sebagai jaring pengaman karena banyaknya tenaga kerja tidak terampil dan lemahnya serikat buruh sehingga memiliki bargaining power yang rendah.

Upah adalah sumber penghasilan, bila sumber penghasilan turun atau tetap maka kesejahteraan juga turun atau tetap dan itu juga pasti akan mempengaruhi tingkat kemiskinan. Banyak tenaga kerja di Indonesia yang memperoleh upah masih dibawah nilai standar untuk memenuhi kebutuhan hidupnya, jika upah yang diterima masyarakat rendah maka akan terjadi lingkaran kemiskinan karena mahalnya biaya hidup maupun pendidikan di Indonesia. Hal tersebut tidak sesuai dengan ajaran agama islam yang 
menekankan prinsip keadilan dalam pemberian upah, islam tidak memperbolehkan umatya untuk berlaku dzalim kepada pekerja atau buruh. Oleh sebab itu pmerintah menetapkan upah minimum agar pekerja memperoleh hak upah sesuai dengan yang dikerjakannya. Jika efektif, upah minimum dapat digunakan sebagai salah satu alat untuk mengurangi kemiskinan karena dapat membantu penduduk miskin untuk keluar dari kemiskinan.

\section{Hubungan Pembangunan Manusia Berbasis Maqashid Syariah (IHDI) dengan Kemiskinan}

Pembangunan manusia atau peningkatan kualitas sumber manusia menjadi hal yang sangat penting dalam strategi kebijakan pembangunan nasional dan pengentasan kemiskinan. Pembangunan manusia di suatu wilayah diukur melalui Indeks Pembangunan Manusia (IPM atau Human Development Index) yang telah diperkenalkan oleh UNDP pada tahun 1990. IPM dibangun melalui pendekatan tiga dimensi dasar, dimensi tersebut mencakup umur panjang dan sehat, pengetahuan dan standar hidup layak. Keberadaan IPM yang diawarkan oleh United Nations Development Program (UNDP) sebagai salah satu alat yang dipakai untuk mengukur tingkat pembangunan manusia mungkin dapat menjadi indikator yang paling komprehensif, tetapi tidak sepenuhnya kompatibel dan cukup untuk mengukur pembangunan manusia dalam perspektif islam. Teori dan konsep yang mendasari untuk pembangunan HDI tidak didasarkan pada maqashid syariah. Untuk mengukur tingkat pembangunan manusia di negara yang mayoritas penduduknya beragama islam akan lebih tepat jika dilakukan dengan menggunakan pembangunan manusia berbasis maqashid Syariah atau Islamic Human Development Index (IHDI) yang mana teori dan konsepnya berdasarkan pada perspektif islam.

IHDI mengukur pencapaian tingkat kesejahteraan manusia dengan terpenuhinya kebutuhan (maslahah) dasar agar manusia dapat hidup bahagia di dunia dan akhirat (mencapai falah). Mayoritas penduduk Kabupaten Grobogan beragama Islam, sedangkan pemeluk agama Protestan, Katolik, Hindu, Budha dan lainnya jumlahnya kurang dari 2\% dari seluruh penduduk, maka akan lebih tepat jika menggunakan pembangunan manusia berbasis maqashid Syariah (IHDI) yang mana teori dan konsepnya berdasarkan perspektif islam. Jika IHDI di Kabupaten Grobogan meningkat maka kemiskinan akan menurun.

Semua variabel penelitian tersebut akan dianalisis apakah memiliki pengaruh terhadap kemiskinan di Kabupaten Grobogan. Secara ringkas kerangka pemikiran penelitian adalah: 


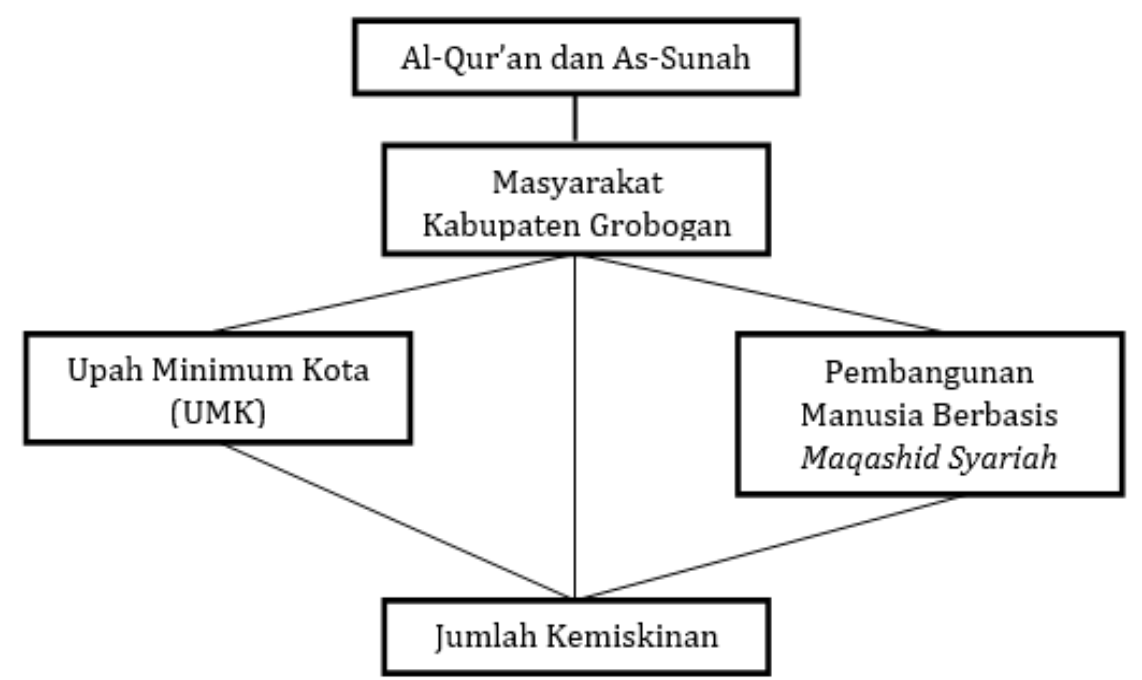

Gambar 1. Kerangka Berpikir Penelitian

Berdasarkan paparan pengembangan hipotesis tersebut, dapat disimpulkan hipotesis penelitian ini adalah:

H1 : Upah Minimum Kota berpengaruh negatif dan signifikan terhadap kemiskinan di Kabupaten Grobogan

H2 : Pembangunan Manusia Berbasis Maqashid Syariah berpengaruh negatif dan signifikan terhadap kemiskinan di Kabupaten Grobogan

\section{Metodologi Penelitian}

Penelitian ini merupakan penelitian kuantitatif dengan menggunakan paradigma positivistik. Penelitian ini merupakan jenis penelitian studi kasus yaitu pada Kabupaten Grobogan Jawa Tengah. Populasi dalam penelitian ini adalah Upah Minimum Kota (UMK) dan Pembangunan Manusia Berbasis Maqashid Syariah dan jumlah kemiskinan Kabupaten Grobogan. Sampel yang digunakan dalam penelitian ini adalah sampel jenuh. Jumlah sampel data penelitian yang digunakan adalah data Upah Minimum Kota, Pembangunan Manusia Berbasis Maqashid Syariah dan jumlah kemiskinan pada tahun 2011 sampai tahun 2017. Penulis memilih tahun 2011-2017 dikarenakan mulai tahun 2011 BPS menggunakan komponen yang berbeda untuk menghitung indeks pembangunan manusia. Variabel Upah Minimum Kota/Kabupaten menggunakan data yang digunakan adalah Upah Minimum Kota (UMK) yang berlaku di Kabupaten Grobogan pada tahun 2011 sampai tahun 2017 yang dinyatakan dalam satuan rupiah per bulan. Variabel pembangunan manusia berbasis Maqashid Syariah (IHDI) menggunakan indikator yang ada pada Tabel 2. 
Pengaruh Upah Minimum Kabupaten/Kota...

Tabel 2. Indikator IHDI

\begin{tabular}{|c|c|c|c|c|}
\hline Perlindungan & Komponen IHDI & $\begin{array}{c}\text { Nilai } \\
\text { Maksimum }\end{array}$ & $\begin{array}{c}\text { Nilai } \\
\text { Minimum }\end{array}$ & Keterangan \\
\hline Agama & Angka Kriminalitas & - & - & - \\
\hline Jiwa & Angka Harapan Hidup & 85 & 20 & $\begin{array}{l}\text { Standar } \\
\text { UNDP }\end{array}$ \\
\hline Akal & $\begin{array}{l}\text { Harapan Lama Sekolah } \\
\text { Rata-rata Lama Sekolah }\end{array}$ & $\begin{array}{l}18 \\
15\end{array}$ & $\begin{array}{l}0 \\
0\end{array}$ & $\begin{array}{l}\text { Standar } \\
\text { UNDP } \\
\text { Standar } \\
\text { UNDP }\end{array}$ \\
\hline Keturunan & Rata-rata Umur Menikah & 25 & 21 & $\begin{array}{l}\text { Standar } \\
\text { BKKBN }\end{array}$ \\
\hline Harta & $\begin{array}{l}\text { Pengeluaran Perkapita } \\
\text { Rill }\end{array}$ & 26.572 .352 & 1.007 .436 & $\begin{array}{l}\text { Standar } \\
\text { Nasional }\end{array}$ \\
\hline
\end{tabular}

Sumber: BPS, 2019

Kemudian dalam perhitungan I-HDI yaitu dengan menghitung indeks yang mencakup lima indikator yang sudah ditentukan sebelumnya yaitu sebagaimana yang dilakukan oleh (Nafilah, 2016) sebagai berikut:

1) Index ad-Dien

Untuk menghitung index ad-Dien, maka dalam penelitian ini digunakan data kriminalitas yang diperoleh dari BPS Kabupaten Grobogan. Angka kriminalitas dapat digunakan sebagai indikator index ad-Dien karena dapat dipakai sebagai salah satu cerminan terhadap pelaksanaan salah satu ibadah terpenting dalam rukun islam yaitu shalat. Hal ini sesuai dengan ayat Al-Qur'an surah Al-Ankabut ayat 45 yang artinya: "Bacalah Kitab (Al-Qur'an) yang telah diwahyukan kepadamu (Muhammad) dan laksanakanlah shalat. Sesungguhnya shalat itu mencegah dari (perbuatan) keji dan mungkar. Dan (ketahuilah) mengingat Allah (shalat) itu lebih besar dari ibadah yang lain. Allah mengetahui apa yang kamu kerjakan."

2) Index an-Nafs

Untuk menghitung index an-Nafs, maka dalam penelitian ini digunakan data angka usia harapan hidup, dengan perhitungan sebagai berikut:

$$
\text { INF }=\frac{\text { Aktual Life Expetancy }- \text { Nilai Minimum }}{\text { Nilai Maksimum }- \text { Nilai Minimum }}
$$

Keterangan:

INF

: Index an-Nafs

Akt. Life E : Nilai aktual angka harapan hidup ke-i

Nilai Min. : Nilai minimal dari komponen I-HDI

Nilai Max. : Nilai maksimal dari komponen I-HDI

Penggunaan indikator ini dirasakan sudah cukup untuk mengukur

IQTISHODUNA Vol. 16 (1), 2020 | 49 http://ejournal.uin-malang.ac.id/index.php/ekonomi 
Ria Safitri, Jadzil Baihaqi, Supriyadi

dimensi an-Nafs, karena angka harapan hidup mencerminkan dimensi umur panjang dan sehat. Semakin panjang umur yang dapat di tempuh seseorang, maka hal tersebut dapat mencerminkan kualitas kesehatan seseorang yang semakin baik.

3) Index al-'Aql

Nilai index al-'Aql dalam perhitungannya diperoleh dari gabungan dua data yang digunakan, yaitu digunakan data angka harapan lama sekolah dan data rata-rata lama sekolah. Kedua indikator ini dapat dimaknai sebagai ukuran kualitas sumber daya manusia dan kedua indikator tersebut juga dipakai dalam penghitungan HDI yang mewakili pengetahuan. Perhitungan index al-'Aql dilakukan sebagai berikut:

$$
\begin{aligned}
& \text { HLS }=\frac{\text { Aktual HLS }- \text { Nilai Minimum }}{\text { Nilai Maksimum }- \text { Nilai Minimum }} \\
& \text { MYSI }=\frac{\text { Aktual MYS }- \text { Nilai Minimum }}{\text { Nilai Maksimum }- \text { Nilai Minimum }} \\
& \mathrm{IA}=\frac{1}{2}(\mathrm{LI})+\frac{1}{3} \text { (MYSI) }
\end{aligned}
$$

Keterangan:

$\begin{array}{ll}\text { IA } & \text { : Index al-'Aql } \\ \text { HLS } & \text { : Harapan Lama Sekolah } \\ \text { MYSI } & \text { : Mean Years School Index } \\ \text { Akt. HLS: Nilai aktual harapan lama sekolah ke-i } & \text { : Nilai aktual rata-rata lama sekolah ke-i } \\ \text { Akt. MYS } & \text { : Nilai minimal dari komponen I-HDI } \\ \text { Nilai Min } & \text { : Nilai maksimal dari komponen I-HDI } \\ \text { Nilai Max } & \end{array}$

4) Index an-Nasl

Perhitungan index an-Nasl dalam penelitian ini yaitu data rata-rata umur menikah atau umur kawin pertama.Umur kawin pertama diartikan sebagai saat dimulainya masa reproduksinya pembuahan. Dengan semakin produktifnya umur menikah, maka kesempatan untuk mendapat keturunan juga semakin besar(Rizky Rahmatullah, 2018)

Perhitungan index an-Nasl akan dilakukan dengan rumus sebagai berikut:

$$
\text { INS }=\frac{\text { Aktual UKP }- \text { Minimal UKP }}{\text { Maksimal UKP }- \text { Minimal UKP }}
$$

Keterangan:

INS : Index an-Nasl

Akt. UKP : Nilai aktual umur kawin pertama

Min UKP : Nilai aktual terendah umur kawin pertama

Max UKP : Nilai aktual tertinggi umur kawin pertama 
5) Index al-Maal

Index al-Maal terbentuk dari gabungan dua indikator yaitu pengeluaran per kapita disesuaikan (PP) sebagai cerminan terhadap kepemilikan harta. Data pengeluaran per kapita disesuaikan (PP) dirubah menjadi angka indeks guna membentuk index al-Maal,Untuk mengukur perlindungan harta (al-Maal) digunakan indikator pengeluaran perkapita yang disesuaikan (daya beli) sebagai cerminan terhadap kepemilikan harta oleh individu. Daya beli merupakan kemampuan masyarakat dalam membelanjakan uangnya untuk barang dan jasa. Kemampuan ini sangat dipengaruhi oleh harga-harga riil antar wilayah karena nilai tukar yang digunakan dapat menurunkan atau menaikkan nilai daya beli. Index al-Maal dengan rumus perhitungan sebagai berikut:(Rizky Rahmatullah, 2018)

$$
\mathrm{IM}=\frac{\text { Aktual PP }- \text { Minimal PP }}{\text { Maksimal PP }- \text { Minimal PP }}
$$

Keterangan:

IM : Index al-Maal

Akt. PP : Nilai aktual pengeluaran perkapita

Min PP : Nilai aktual terendah pengeluaran perkapita

Max PP : Nilai aktual tertinggi pengeluaran perkapita

Setelah nilai dari kelima indeks perlindungan telah diketahui, maka nilai Islamic Human Development Index (I-HDI), Material Welfare Index (MWI), dan Non-Material Welfare Index (NWI) dapat di hitung dengan rumus perhitungan rata-rata aritmatika sebagai berikut:

$$
\begin{aligned}
& \mathrm{IHDI}=\frac{2}{5}(\mathrm{ID})+\frac{1}{5}(\mathrm{INF}+\mathrm{IA}+\mathrm{INS}+\mathrm{IM}) \times 100 \\
& \mathrm{MWI}=\mathrm{PPI} \\
& \mathrm{NWI}=\frac{1}{4}(\mathrm{IND}+\mathrm{INF}+\mathrm{IA}+\mathrm{INS})
\end{aligned}
$$

Keterangan:

I-HDI : Islamic Human Development Index

MWI : Material Welfare Index

NWI : Non-Material Welfare Index

ID : Index ad-Dien

INF : Index an-Nafs

IA : Index al-'Aql

INS : Index an-Nasl

IM : Index al-Maal

DEI : Distributional Equity Index

PPI : Pengeluaran perkapita Index

IQTISHODUNA Vol. 16 (1), 2020 | 51 http://ejournal.uin-malang.ac.id/index.php/ekonomi 
Ria Safitri, Jadzil Baihaqi, Supriyadi

Sedangkan variabel kemiskinan dipandang sebagai ketidakmampuan dari sisi ekonomi untuk memenuhi kebutuhan dasar makanan dan bukan makanan. Dalam implementasinya dihitunglah garis kemiskinan berdasarkan kebutuhan makanan dan bukan makanan. Penduduk yang memiliki rata-rata pengeluaran atau pendapatan per kapita per bulan di bawah garis kemiskinan disebut penduduk miskin (Kemenkominfo, 2011). Data yang digunakan adalah jumlah kemiskinan Kabupaten Grobogan dalam kurun waktu 2011-2017 yang diukur dalam persen.

Data penelitian ini dianalisis dengan Teknik analisis regresi linier berganda. Sebelum melakukan analisis regresi linier berganda, data diuji dengan uji asumsi klasik yang bertujuan untuk mengetahui apakah terjadi bias atau tidak. Teknik pengujian yang dipakai adalah uji multikolonieritas, uji autokorelasi, uji heteroskedastisitas, dan uji normalitas. Data time series yang dikumpulkan dalam penelitian ini dianalisis dengan menggunakan bantuan software Eviews 7.

\section{Hasil Penelitian}

\section{Gambaran Objek Penelitian}

Jumlah penduduk Kabupaten Grobogan pada tahun 2018 tercatat sebesar 1.459.780 jiwa, mengalami pertumbuhan penduduk 0,69\% atau bertambah 9.989 jiwa bila dibandingkan dengan tahun 2017. Kepadatan Penduduk tercatat sebesar 739 jiwa/km2, dengan wilayah terpadat terletak di Kecamatan Purwodadi sebesar 1.794 jiwa/km2 dan terendah di Kecamatan Geyer sebesar 342 jiwa/km2.

Jumlah penduduk miskin selama enam tahun terakhir selalu mengalami penurunan, mulai dari 14,87\% pada tahun 2013 dan berurutan mengalami penurunan menjadi $13,86 \%$ pada tahun $2014,13,68 \%$ pada tahun 2015 , $13,57 \%$ pada tahun $2016,13,3 \%$. pada tahun 2017 , dan pada akhir tahun 2018 sebesar 12,31\%.Dilihat dari komposisi tingkat pendidikan penduduk, tamat SD atau sederajat sebanyak 41,30\%, tidak atau belum tamat SD sebanyak 28,91\%, tamat SLTP atau sederajat 17,26\%, tamat SLTA atau sederajat 10,11\%, dan tamat Akademisi, S1, S2, S3 sebanyak 2,42\%.Selanjutnya dari Indeks Pembangunan Manusia, Kabupaten Grobogan selama lima tahun terakhir masuk kategori sedang dan selalu mengalami kenaikan, mulai dari 68,05 pada tahun 2015 menjadi 68,87 pada tahun 2017. 


\section{Hasil Uji Asumsi Klasik}

Hasil uji asumsi klasik dapat dilihat dalam Tabel 3 berikut:

Tabel 3. Ringkasan Hasil Uji Asumsi Klasik

\begin{tabular}{|c|c|c|c|}
\hline Uji & Indikator & Hasil & Kesimpulan \\
\hline Normalitas & $\begin{array}{l}\text { Nilai Probability } \\
\text { Jarque Bera (JB) } \\
>5 \%\end{array}$ & $\begin{array}{l}\text { Nilai Probability } \\
\text { Jarque Bera (JB) } \\
0.957513\end{array}$ & $\begin{array}{l}\text { Data residual } \\
\text { berdistribusi normal }\end{array}$ \\
\hline Multikolinieritas & Centered VIF $<10$ & $\begin{array}{l}\text { UMK } 2.407606 \\
\text { IHDI } 2.407606\end{array}$ & $\begin{array}{l}\text { Tidak terdapat } \\
\text { multikolinieritas }\end{array}$ \\
\hline Heteroskedastisitas & $\begin{array}{l}\text { Metode Breusch- } \\
\text { Pagan-Godfrey } \\
\text { Nilai Probability } \\
\text { Obs*R-squared > } \\
5 \%\end{array}$ & $\begin{array}{l}\text { Prob. Chi- } \\
\text { square(2) Obs*R- } \\
\text { squared } 0.2016\end{array}$ & $\begin{array}{l}\text { Tidak terdapat } \\
\text { heteroskedastisitas }\end{array}$ \\
\hline Autokorelasi & $\begin{array}{l}\text { Metode Breusch- } \\
\text { Godfrey Serial } \\
\text { Correlation LM } \\
\text { Nilai Probability } \\
\text { Obs*R-squared > } \\
5 \%\end{array}$ & $\begin{array}{l}\text { Prob. Chi- } \\
\text { square(2) Obs*R- } \\
\text { squared } 0.1971\end{array}$ & $\begin{array}{l}\text { Tidak terdapat } \\
\text { autokorelasi }\end{array}$ \\
\hline
\end{tabular}

Sumber : Data primer diolah, 2019

\section{Hasil Uji Regresi Linier Berganda}

Hasil uji regresi linier berganda dapat dilihat dalam Tabel 4 . Berdasarkan hasil output regresi linier berganda persamaan regresinya adalah sebagai berikut:

\section{Ln Miskin $=$ 8.8761-0.3876*LnUMK $-0.1995 *$ LnIHDI}

Angka R-Square sebesar 0,684 atau (68,4\%). Hal ini menunjukkan bahwa presentase sumbangan pengaruh variabel independen (UMK dan IHDI) mampu menjelaskan variabel dependen (Jumlah Kemiskinan) sebesar 68,4\%. Sedangkan sebesar 31,6\% dipengaruhi atau dijelaskan oleh variabel lain yang tidak dimasukkan dalam model penelitian ini.

Nilai $\mathrm{F}$ hitung $>\mathrm{F}$ tabel $=7,51>6,94$, maka $\mathrm{H}_{0}$ ditolak. Karena Nilai $\mathrm{F}$ hitung $>\mathrm{F}$ tabel $=7,51>6,94$, artinya ada pengaruh secara signifikan antara UMK dan IHDI secara bersama-sama terhadap jumlah kemiskinan.

Variabel UMK $-2.803>2.132$, yaitut hitung $>t$ tabel, sehingga dapat disimpulkan bahwa $\mathrm{H}_{0}$ ditolakdan $\mathrm{H}_{1}$ diterima yang berarti variabel Upah Minimum Kota (X1) berpengaruh negatif dan signifikan terhadap variabel jumlah kemiskinan (Y).

Variabel IHDI $-0,418<2.132$, yaitut hitung $<\mathrm{t}$ tabel, sehingga dapat 
Ria Safitri, Jadzil Baihaqi, Supriyadi

disimpulkan bahwa $\mathrm{H}_{0}$ diterima dan $\mathrm{H}_{1}$ ditolak yang berarti variabel IHDI (X2) tidak berpengaruh atau negatif dan tidak signifikan terhadap jumlah kemiskinan $(\mathrm{Y})$

Tabel 4. Hasil Uji Regresi Linier Berganda

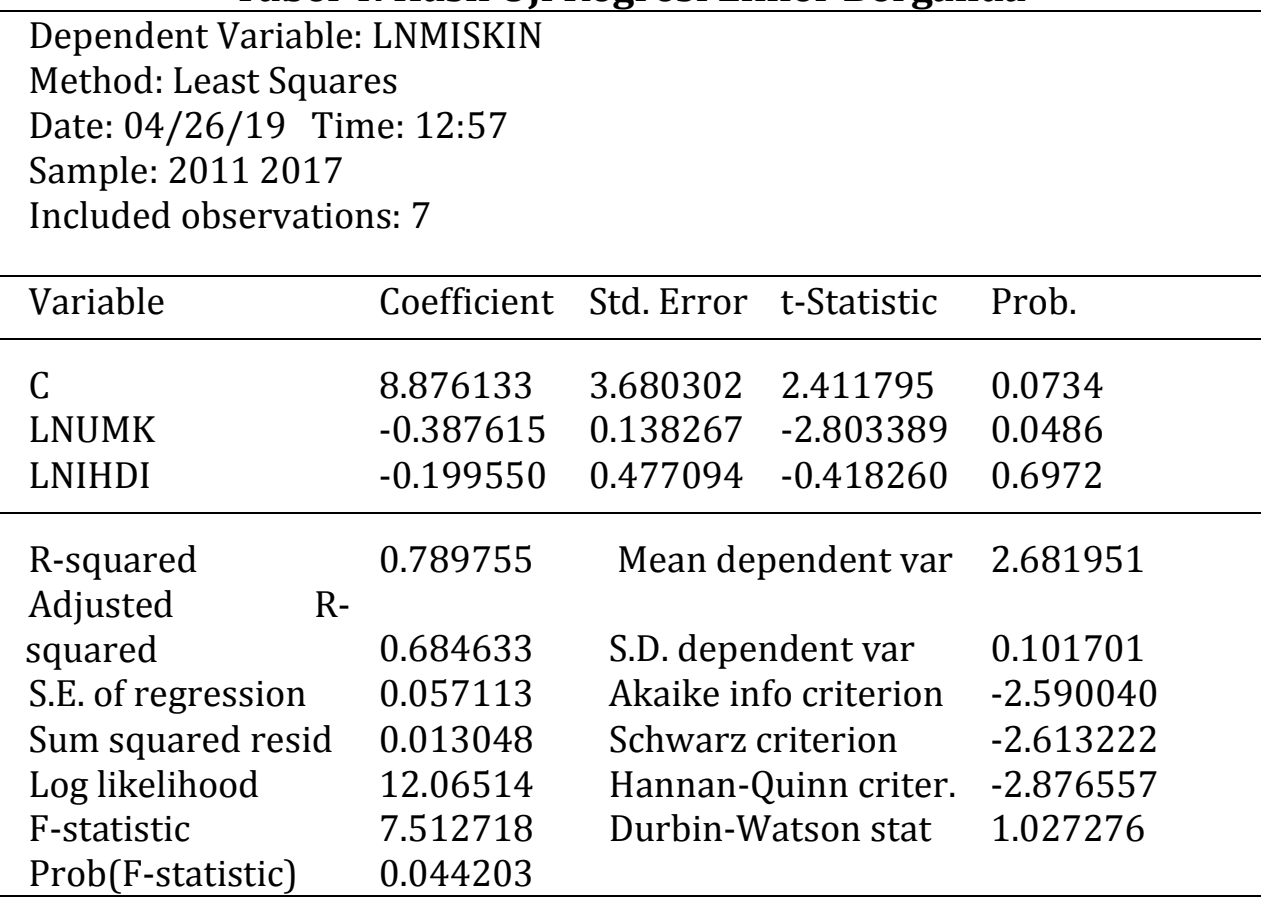

Sumber : Data primer diolah, 2019

\section{Pembahasan}

Hasil uji t untuk variabel Upah Minimum Kota (UMK) adalah mempunyai pengaruh yang negatif signifikan terhadap jumlah kemiskinan Kabupaten Grobogan tahun 2011-2017. Hal tersebut dibuktikan dengan nilai t hitung sebesar 2.803 yang lebih besar dari t tabel yaitu sebesar 2.132, karenat hitung $<\mathrm{t}$ tabel dengan nilai koefisien regresi $-2,803389$, sehingga dapat disimpulkan bahwa variabel Upah Minimum Kota (X1) berpengaruh negatif dan signifikan terhadap variabel jumlah kemiskinan.

Hasil penelitian ini sesuai dengan penelitian yang dilakukan oleh Lutfi, Wibisono, \& Yuliati (2016), bahwa hasil penelitiannya sesuai dengan tujuan penetapan upahminimum dalam Peraturan Menteri Tenaga Kerja Nomor : Per-01/Men/1999 dan UU Ketenagakerjaan No. 13 tahun 2003, yaitu untuk meningkatkan kesejahteraan pekerja, sehingga terbebas dari kemiskinan. Penetapan upah minimum yang mendekati KHM (Kebutuhan Hidup Minimum) dan diatas garis kemiskinan telah tepat karena mampu menurunkan jumlah penduduk miskin. 
Hasil penelitian ini tidak sesuai dengan penelitian yang dilakukan oleh Ningrum (2017) dan Romi \& Umiyati (2018) yang menyimpulkan bahwa upah minimum berpengaruh positif dan signifikan terhadap jumlah kemiskinan di Indonesia. Ningrum mengatakan bahwa mayoritas pekerjaan masyarakat Indonesia adalah bekerja pada sektor informal sedangkan upah minimum hanya berlaku pada sektor formal.

Upah minimum bernilai negatif dan signifikan karena jika tingkat pendapatan semakin tinggi, maka akan meningkatkan kesejahteraan masyarakat. Jika tingkat pendapatan masyarakat semakin meningkat, maka kesempatan untuk memperoleh pendidikan yang memadai semakin besar dan kebutuhan hidup masyarakat akan terpenuhi dikarenakan mahalnya biaya pendidikan dan biaya hidup di Indonesia. Dengan demikian, upah minimum kota sangat berkontribusi besar dalam menurunkan jumlah kemiskinandi Kabupaten Grobogan dan perlindungan hak pekerja agar memperoleh upah sesuai apa yang diusahakannya. Hal tersebut sesuai dengan firman Allah di dalam Al-Qur'an surah An-Najm ayat 39 yang artinya: "Dan bahwasanya seorang manusia tiada memperoleh selain apa yang diusahakannya."

Usaha dan hasil berbanding lurus, semakin besar usaha yang dilakukan maka hasil yang didapatkan juga semakin banyak. Semakin bersungguhsungguh seorang manusia dalam bekeja maka semakin besar upah yang diperolehnya. Untuk menentukan standar upah yang adil, islam mengajarkan bagaimana menetapkan upah yaitu dengan tidak melakukan kezaliman terhadap buruh, sehingga dapat dikatakan bahwa upah yang adil adalah upah yang sepadan dengan pekerjaan yang dilakukannya. Tentu saja penetapan tersebut dengan mempertimbangkan situasi serta faktor-faktor yang berkaitan dengan nilai pekerjaan. Keadilan dalam pemberian upah sangat perlu diperhatikan, karena salah satu faktor terjadinya lingkaran kemiskinan disebabkan masih banyaknya masyarakat yang memiliki pendapatan rendah sehingga tidak dapat mencukupi kebutuhan hidupnya.

Hasil uji t untuk variabel pembangunan manusia berbasis maqashid Syariah (IHDI) adalah berpengaruh negatif dan tidak signifikan terhadap jumlah kemiskinan di Kabupaten Grobogan. Hal tersebut dibuktikan dengan nilai t hitung sebesar 0,418 yang lebih kecil dari t tabel sebesar 2.132, karena t hitung $<\mathrm{t}$ tabel dengan nilai koefisien regresi -0,418260, sehingga dapat disimpulkan bahwa variabel pembangunan manusiaberbasis maqashid Syariah (X2) berpengaruh negatif tidak signifikan terhadap variabel jumlah kemiskinan (Y).

IQTISHODUNA Vol. 16 (1), 2020 | 55 
Hasil penelitian ini sesuai dengan penelitian Nafilah (2016) yang menunjukkan bahwa variabel Islamic Human Development Index atau pembangunan manusia berbasis maqashid Syariah hasilnya negatif dan tidak signifikan terhadap jumlah kemiskinan. Menurut Nafilah hasil tidak signifikan ini disebabkan oleh standar kemiskinan yang dipakai murni dari standar pendapatan semata, sedangkan komponen lain tidak dapat langsung dikaitkan dengan jumlah kemiskinan moneter.

Variabel pembangunan manusia berbasis maqashid Syariah (IHDI) berpengaruh negatif dan tidak signifikan, hal tersebut terjadi karena pengukuran kemiskinan yang digunakan oleh Badan Pusat Statistik menggunakan konsep kemampuan memenuhi kebutuhan dasar (basic need approach) (BPS, 2019). Dengan pendekatan ini, kemiskinan dipandang sebagai ketidakmampuan dari sisi ekonomi untuk memenuhi kebutuhan dasar makanan dan bukan makanan yang diukur dari sisi pengeluaran dan pendapatan, sehingga komponen lain tidak dapat langsung dikaitkan dengan kemiskinan yang dimaksudkan oleh BPS tersebut. Oleh sebab itu, pembangunan manusiaberbasis maqashid Syariah (IHDI) lebih tepat memotret kemiskinan yang dikaji dari sudut pandang multidimensional.

\section{Kesimpulan}

Berdasarkan hasil perhitungan dan analisis dari pengaruh variabel upah minimum kota dan pembangunan manusia berbasis maqashid syariah terhadap jumlah kemiskinan di Kabupaten Grobogan, maka dapat ditarik kesimpulan bahwa variabel upah minimum kota berpengaruh negatif dan signifikan terhadap jumlah kemiskinan di Kabupaten Grobogan. Sedangkan variabel pembangunan manusia berbasis maqashid syariah berpengaruh negatif dan tidak signifikan terhadap jumlah kemiskinan di Kabupaten Grobogan. Hal tersebut terjadi karena pengukuran kemiskinan yang digunakan oleh Badan Pusat Statistik menggunakan konsep kemampuan memenuhi kebutuhan dasar (basic need approach). Dengan pendekatan ini, kemiskinan dipandang sebagai ketidakmampuan dari sisi ekonomi untuk memenuhi kebutuhan dasar makanan dan bukan makanan yang diukur dari sisi pengeluaran dan pendapatan, sehingga komponen lain tidak dapat langsung dikaitkan dengan kemiskinan yang dimaksudkan oleh BPS tersebut.

\section{Daftar Pustaka}

Anto, M. H. (2011). Introducing an Islamic Human Development Index (I-HDI) to Measure Development in OIC Countries. The Islamic Research and 
Pengaruh Upah Minimum Kabupaten/Kota...

Training Institute (IRTI), 19. Pp: 69-95. Retrieved from https://ideas.repec.org/a/ris/isecst/0024.html

BPS. (2019). Kemiskinan dan Ketimpangan. Retrieved from https://www.bps.go.id/subject/23/kemiskinan-dan-ketimpangan.html

Isdijoso, W., Suryahadi, A., \& Akhmadi, A. (2016). Penetapan Kriteria dan Variabel Pendataan Penduduk Miskin yang Komprehensif dalam Rangka Perlindungan Penduduk Miskin di Kabupaten/Kota. Jakarta. Retrieved from

http://www.smeru.or.id/sites/default/files/publication/cbms_criteria_ ind.pdf

Kemenkominfo. (2011). Program Penanggulangan Kemiskinan Kabinet Indonesia Bersatu II. Jakarta. Retrieved from https://web.kominfo.go.id/sites/default/files/Program Penanggulangan Kemiskinan Kabinet Indonesia Bersatu II.pdf

Kurniawati, A., Gunawan, B. T., \& Indrasari, D. P. R. (2017). Dampak Upah Minimum Terhadap Kemiskinan di Indonesia Tahun 2006-2014. Jurnal Riset Ekonomi Dan Manajemen. 17(2). Pp: 233-252. https://doi.org/http://dx.doi.org/10.17970/jrem.17.170207.ID

Lutfi, A. F., Wibisono, S., \& Yuliati, L. (2016). Pengaruh Upah Minimum Kabupaten/Kota (UMK), Indeks Pembangunan Manusia (IPM) dan Pengangguran Terhadap Jumlah Penduduk Miskin di Provinsi Jawa Timur Periode 2006-2013. Artikel Ilmiah Mahasiswa. Retrieved from http://repository.unej.ac.id/bitstream/handle/123456789/74647/AH MAD FATHUL LUTFI.pdf?sequence $=1$

Nafilah, A. A. (2016). Pengaruh Pertumbuhan Ekonomi, Pengangguran, dan Islamic Human Development Index Terhadap Kemiskinan di Kabupaten Jeneponto, Provinsi Sulawesi Selatan Tahun 2005-2014. Universitas Airlangga. Retrieved from http://repository.unair.ac.id/55723/13/FEB.EI. 144-16 Aal p-min.pdf

Ningrum, S. S. (2017). Analisis Pengaruh Tingkat Pengangguran Terbuka, Indeks Pembangunan Manusia, Upah Minimum Terhadap Jumlah penduduk Miskin Di Indonesia Tahun 2011-2015. Jurnal Ekonomi Pembangunan. 15(2). Pp: 184-192. https://doi.org/https://doi.org/10.22219/jep.v15i2.5364

Rahmatullah, R. (2018). Islamic Human Development Index di Kawasan Eksplorasi Tambang Batu Bara di Batu Sopang Kalimantan Timur. Universitas Islam Indonesia. Retrieved from https://dspace.uii.ac.id/handle/123456789/8417

Ridwan, M. (2013). Standar Upah Pekerja Menurut Sistem Ekonomi Islam. 
Ria Safitri, Jadzil Baihaqi, Supriyadi

Equilibrium, 1(2). Pp: 241-257.

Romi, S., \& Umiyati, E. (2018). Pengaruh pertumbuhan ekonomi dan upah minimum terhadap kemiskinan di Kota Jambi. E-Jurnal Perspektif Ekonomi Dan Pembangunan Daerah, 7(1). Retrieved from https://online-journal.unja.ac.id/index.php/pdpd/article/view/4439

Septiarini, M. M., \& Herianingrum, S. (2017). Analisis I-HDI (Islamic Human Development Index) di Jawa Timur. Jurnal Ekonomi Syariah Teori Dan Terapan. 4(5). Pp: 381-395. Retrieved from https://ejournal.unair.ac.id/JESTT/article/view/6886 